\title{
KONSEP PENGUPAHAN DALAM MANAJEMEN SYARIAH
}

\author{
Wiwin Agustian ${ }^{1}$, Dina Mellita ${ }^{2}$ \\ Manajemen, Fakultas Ekonomi dan Bisnis Universitas Bina Darma \\ wiwinagustian@binadarma.ac.id ${ }^{1}$, dinamellita@binadarma.ac.id ${ }^{2}$
}

\begin{abstract}
As to person reason wants to work (Peterson and Plowman); the desire to live (willing for alive continuance), the desire for posession (willing to has a certain), the desire for power (willing to has power), the desire for recornation (willing for acknowledgement). wage follows west wage or salary usually, main or minimum and every emolumen addition that payed out direct or not direct, what in the form of cash or goods, by entrepreneur to worker in relation to work connection. while wage follows Islam repayment that accepted somebody on the job in the form of matter repayment at world (fair and proper) and in the form of reward repayment at akherat (repayment good). opinion difference towards wage between west and Islam situated in 2 matters: first, Islam see wage very big the hook with moral concept, temporary west not. second, wage in Islam not only limit of matter (matter or mundane) but menembus life limit, that is berdimensi akherat that called with reward, temporary west not. as to wage concept second similarity between west and Islam lays in justice principle (justice) and elegibility principle (sufficiency).
\end{abstract}

Keyword : Payment Management Syariah, Konvensional Payment

\begin{abstract}
ABSTRAK
Sebagaimana alasan keinginan orang bekerja (Peterson dan Plowman); keinginan untuk hidup (kelangsungan hidup), keinginan untuk memiliki posisi, keinginan untuk kekuasaan, keinginan untuk pemulihan (keinginan untuk pengakuan). Biasanya upah dan gaji mengikuti metode pengupahan barat (konvensional), berupa komponen pokok (gaji) atau minimum upah dan setiap penambahan emolumen yang dibayarkan langsung atau tidak langsung, baik dalam bentuk uang tunai ataupun barang, oleh pengusaha ke pekerja sehubungan dengan hubungan kerja. Sementara upah mengikuti pembayaran Islam yang diterima seseorang dalam hubungan pekerjaan berbentuk pembayaran materi di dunia (adil dan tepat) dan dalam bentuk pembayaran imbalan di akherat (pahala). Perbedaan pendapat terhadap upah antara barat dan Islam terletak dalam 2 hal: pertama, Islam melihat upah sangat besar kaitannya dengan konsep moral, sementara barat tidak. kedua, upah dalam Islam tidak hanya membatasi materi (materi atau duniawi) tetapi menembus batas kehidupan, yaitu berdimensi akherat yang disebut dengan imbalan pahala, sementara barat tidak. Untuk persamaan kedua konsep antara barat dan Islam terletak pada prinsip keadilan dan prinsip elegibilitas (kecukupan).
\end{abstract}

Kata Kunci : Pengupahan dalam Manajemen Syariah, Pengupahan Konvensional 


\section{P E N D A H U L UA N}

Dalam kenyataan ada sejumlah kenyataan yang membuktikan bahwa uang merupakan hal yang penting bagi pegawai. Karena uang bernilai sehingga dapat ditukarkan dengan barang barang atau jasa. Uang memiliki nilai ekonomik sebagai alat tukar untuk alokasi sumber daya ekonomi dan juga merupakan alat tukar sosial. Berdasarkan alasan tersebut maka orang mau bekerja. Adapun alasan orang mau bekerja (petersonand plowman)

1. The desire to live (keinginan untuk kelangsungan hidup)

2. The desire for posession (keinginan untuk memiliki sesuatu)

3. The desire for power (keinginan untuk memiliki kekuasaan)

4. The desire for recornation (keinginan untuk pengakuan)

Sehingaa masalah dalam pemberian jasa adalah masalah yang tidak pernah selesai diperdebatkan oleh pihak manajemen, apapun bentuk organisasinya. Balasa jasa yang selalu membuat pihak manajemen perusahaan berpikir ulang dari waktu ke waktu untuk menetapkan kebijakan tentang balas jasa. Dalam suatu organisasi upah sering memicu konflik antara pihak manajemen dengan karyawan seperti yang banyak terjadi akhir-akhir ini.
Bagi organisasi paling penting adalah bagaimana manajemen pengupahan sehingga dapat menentukan perbedaan besar tingkat upah yang diterima. Seperti pengalaman bekerja, imbalan yang diterima di tempat lain menjadi pertimbangan untuk penentuan gaji pegawai. Ada juga fakta di mana insentif yang dibagikan kepada pegawai sering menimbulkan protes karyawan. Seharusnya jika organisasi memberikan insentif kepada pegawai karena berprestasi, maka pegawai bersyukur dan berterimakasih kepada organisasi. Tetapi yang sering terjadi pegawai sering melakukan protes karena insentif yang diterimanya lebih kecil dari yang diharapkannya. Sebagian lagi protes karena pegawai yang merasa pekerjaan dan tugasnya sama, namun insentif yang diterimanya berbeda-beda.

Berdasarkan kondisi yang telah diuraikan, maka konsep pengupahan dalam manajemen syariah menjadi penting untuk diteliti, bagaimana sebenarnya konsep pengupahan dalam manajemen syariah dalam menggariskan aturan tentang pengupahan tersebut.

\section{I.1. PERUMUSAN MASALAH}

Berdasarkan latar belakang diatas sering timbul perntanyaan menjadi masalah dalam pemberian balas jasa atau 
manajemen upah, maka yang menjadi masalah adalah :

"Bagimana konsep upah pada manajemen syariah (Islam) dan konsep pengupahan pada konsep konvensional (barat)".

\subsection{TUJUAN}

Tujuan penelitian ini adalah menjelaskan konsep dan pengupahan yang sesuai dengan ketentuan-ketentuan syariah. Sehinggan tujuan penelitian ini adalah “ untuk mengetahui dan menganalisis bagaimana konsep upah pada manajemen syariah (Islam) dan konsep konvensional (barat) “

\section{TINJAUAN PUSTAKA}

\subsection{Upah dan Gaji.}

Upah atau Gaji biasa, pokok atau minimum dan setiap emolumen tambahan yang dibayarkan langsung atau tidak langsung, apakah dalam bentuk uang tunai atau barang, oleh pengusaha kepada pekerja dalam kaitan dengan hubungan kerja . Ciri sistem pemberian balas jasa yang baik adalah mudah dimengerti, mudah dihitung, motivasi efektif, adanya hubungan antara kerja dan upah serta stabil.(Ruky:2001)

\subsection{Falsafah dan Faktor Upah}

Falsafah dari pemberian upah adalah adil dan kompetitif, adil disini menjelaskan bahwa sesuatu adalah objektif, sedangkan kompetetitif menggambarkan bahwa tidak kalah dengan sistem imbalan dalam organisasi sejenis, (Davis,1995) .

Faktor internal dalam kebijakan imbalan, Kemampuan Perusahaan untuk Membayar, Karakteristik Pekerjaan, Karakteristik Pekerja .Faktor eksternal dalam kebijakan imbalan, Keadaan Pasar Tenaga Kerja, Standar Biaya Hidup, Tingkat Upah Industri Sejenis, Peraturan Pemerintah Mengenai Imbalan (Desler,2004)

\subsection{Upah menurut pandangan Islam}

Menurut Defenisi Muhammad Abduh dan Zamakhsari, maka seorang yang bekerja pada suatu badan usaha (organisasi) dapat dikategorikan sebagai amal saleh, dengan syarat perusahaannya tidak memproduksi/menjual atau mengusahakan barang-barang yang haram. Dengan demikian, maka seorang karyawan yang bekerja dengan benar, akan menerima dua imbalan, yaitu imbalan di dunia dan imbalan di akherat. (Yusuf Qardhawi, $405,2001)$

Allah menegaskan tentang imbalan ini dalam Qur'an sbb : (Abdul Wahhab Abdul Aziz As- Syaisyani.) "Dan katakanlah : "Bekerjalah kamu, maka Allah dan Rasul- 
Nya serta orang-orang mu'min akan melihat pekerjaanmu itu, dan kamu akan dikembalikan kepada Allah Yang Mengetahui akan ghaib dan yang nyata, lalu diberikan-Nya kepada kamu apa yang kamu kerjakan." (At Taubah : 105).

"Sesungguhnya mereka yang beriman dan beramal saleh tentulah Kami tidak akan menyia-nyiakan pahala orang-orang yang mengerjakan amalan(nya) dengan baik." (Al Kahfi : 30).

Menurut Dewan Penelitian Perupahan Nasional : Upah adalah suatu penerimaan sebagai imbalan dari pemberi kepada penerima kerja untuk suatu pekerjaan atau jasa yang telah dan akan dilakukan, berfungsi sebagai jaminan kelangsungan hidup yang layak bagi kemanusiaan dan produksi, dinyatakan atau dinilai dalam bentuk uang yang ditetapkan menurut suatu persetujuan, undang-undang dan peraturan dan dibayarkan atas dasar suatu perjanjian kerja antara pemberi dan penerima kerja

\section{METODE PENELITIAN}

Penelitian ini adalah penelitian deskriptif. Penulis bermaksud menjelaskan keadaan suatu variabel/ fenomena secara mandiri.

Sesuai tempatnya, penelitian ini berupa studi kepustakaan. Sumber data diambil dari referensi, dokumen-dokumen yang berisi data yang telah teruji validitasnya.

Penelitian ini difokuskan fungsinya untuk memahami fenomena pengupahan dalam manajemen syari'ah. (Sugiyono, 2017: 14)

\section{PEMBAHASAN}

Pada saat pegawai bergabung dengan suatu organisasi, mereka membuat perjanjian ekonomis dan psikologis yang tidak tertulis, meskipun pada umumnya mereka melakukannya secara tidak sadar. Perjanjian psikologis, menetapkan syarat keterlibatan psikologis masing-masing pegawai dengan sistem, dan menuntut lebih dari sekedar imbalan ekonomis, mereka berusaha untuk mendapatkan rasa aman, perlakuan sebagai manusia, hubungan yang baik dengan orang lain, dan dukungan untuk memenuhi harapan. Jika organisasi hanya mementingkan perjanjian ekonomis, kepuasan kerja dan prestasi pegawai akan cenderung menurun. Sebaliknya jika harapan psikologis dan ekonomis mereka terpenuhi, pegawai cenderung merasa puas dan berusaha untuk berprestasi. Upah menurut pengertian Barat terkait dengan pemberian imbalan kepada pekerja tidak tetap, atau tenaga buruh lepas, seperti upah buruh lepas di perkebunan kelapa sawit, upah pekerja bangunan yang dibayar mingguan atau bahkan harian. Sedangkan gaji 
menurut pengertian Barat terkait dengan imbalan uang (finansial) yang diterima oleh karyawan atau pekerja tetap dan dibayarkan sebulan sekali . (Tropman : 2001). Sehingga dalam pengertian barat, Perbedaan gaji dan upah itu terletak pada Jenis karyawannya (Tetap atau tidak tetap) dan sistem pembayarannya (bulanan atau tidak). Meskipun titik berat antara upah dan gaji terletak pada jenis karyawannya apakah tetap ataukah tidak.

Dalam hal perbedaan pengertian upah dan gaji menurut konsep Barat di atas, maka Islam menggariskan upah dan gaji lebih komprehensif dari pada Barat.

Allah menegaskan tentang imbalan ini dalam Qur'an sbb :

Dalam menafsirkan At Taubah ayat 105 ini, Quraish Shihab menjelaskan dalam kitabnya Tafsir Al-Misbah sbb :

"Bekerjalah Кати, demi karena Allah semata dengan aneka amal yang saleh dan bermanfaat, baik untuk diri kamu maupun untuk masyarakat umum, maka Allah akan melihat yakni menilai dan memberi ganjaran amal kamu itu"

Berdasarkan surat diatas suatu organisasi harus berkewajiban menilai dan memberi ganjaran terhadap amal-amal itu. Dengan kata lain daripada ganjaran adalah imbalan atau upah atau compensation.
Sementara menurut Syeikh AzZamakhsari, Amal Saleh adalah segala perbuatan yang sesuai dengan dalil akal, al-Qur'an dan atau Sunnah Nabi Muhammad Saw.

Berdasarkan tiga ayat diatas, yaitu AtTaubah 105, An-Nahl 97 dan

AlKahfi 30, maka Imbalan dalam konsep Islam menekankan pada dua aspek, yaitu dunia dan akherat. Tetapi hal yang paling penting, adalah bahwa penekanan kepada akherat itu lebih penting daripada penekanan terhadap dunia (dalam hal ini materi) sebagaimana semangat dan jiwa Al-Qur'an surat Al-Qhashsash ayat 77.

Surat At Taubah 105 menjelaskan bahwa Allah memerintahkan kita untuk bekerja, dan Allah pasti membalas semua apa yang telah kita kerjakan. Yang paling unik dalam ayat ini adalah penegasan Allah bahwa motivasi atau niat bekerja itu mestilah benar. Sebab kalau motivasi bekerja tidak benar, Allah akan membalas dengan cara memberi azab. Sebaliknya, kalau motivasi itu benar, maka Allah akan membalas pekerjaan itu dengan balasan yang lebih baik dari apa yang kita kerjakan (An-Nahl : 97).

Lebih jauh Surat An-Nahl : 97 menjelaskan bahwa tidak ada perbedaan gender dalam menerima upah / balasan dari Allah. Ayat ini menegaskan bahwa 
tidak ada diskriminasi upah dalam Islam, jika mereka mengerjakan pekerjaan yang sama. Hal yang menarik dari ayat ini, adalah balasan Allah langsung di dunia (kehidupan yang baik/rezeki yang halal) dan balasan di akherat (dalam bentuk pahala).

Sementara itu, Surat Al-Kahfi : 30 menegaskan bahwa balasan terhadap pekerjaan yang telah dilakukan manusia, pasti Allah balas dengan adil. Allah tidak akan berlaku zalim dengan cara menyianyiakan amal hamba-Nya. Konsep keadilan dalam upah inilah yang sangat mendominasi dalam setiap praktek yang pernah terjadi di negeri Islam.

Lebih lanjut kalau kita lihat hadits Rasulullah saw tentang upah yang diriwayatkan oleh Abu Dzar bahwa Rasulullah s.a.w bersabda :

“ Mereka (para budak dan pelayanmu) adalah saudaramu, Allah menempatkan mereka di bawah asuhanmu; sehingga barang siapa mempunyai saudara di bawah asuhannya maka harus diberinya makan seperti apa yang dimakannya (sendiri) dan memberi pakaian seperti apa yang dipakainya (sendiri); dan tidak membebankan pada mereka dengan tugas yang sangat berat, dan jika kamu membebankannya dengan tugas seperti itu, maka hendaklah membantu mereka (mengerjakannya)." (HR. Muslim).
Dari hadits ini dapat didefenisikan bahwa upah yang sifatnya materi (upah di dunia) mestilah terkait dengan keterjaminan dan ketercukupan pangan dan sandang. Perkataan : "harus diberinya makan seperti apa yang dimakannya (sendiri) dan memberi pakaian seperti apa yang dipakainya (sendiri)" , bermakna bahwa upah yang diterima harus menjamin makan dan pakaian karyawan yang menerima upah.

Sehingga dari ayat-ayat Al-Qur'an di atas, dan dari hadits-hadits di atas, maka dapat didefenisikan bahwa : Upah adalah imbalan yang diterima seseorang atas pekerjaannya dalam bentuk imbalan materi di dunia (Adil dan Layak) dan dalam bentuk imbalan pahala di akherat (imbalan yang lebih baik).( Shabuni, Muhammad Ali As-. 1995).

Berdasarkan uraian diatas sehingga dapat terlihat adanya perbedaab anatar konsep upah konvensional (barat) dan konsep upah syariat (Islam). Dimana perbedaan tersebut adalah,

Pertama, Islam melihat Upah sangat besar kaitannya dengan konsep Moral, sementara Barat tidak. Kedua, Upah dalam Islam tidak hanya sebatas materi (kebendaan atau keduniaan) tetapi menembus batas kehidupan, yakni berdimensi akherat yang disebut dengan Pahala, sementara Barat tidak. 
Tabel 1.

Konsep Upah antara Barat dan Islam

\begin{tabular}{|c|c|c|c|}
\hline No & Aspek & Barat & Islam \\
\hline 1 & $\begin{array}{l}\text { Keterkaitan } \\
\text { yang erat } \\
\text { antara upah } \\
\text { dengan } \\
\text { moral }\end{array}$ & Tidak & $\mathrm{Ya}$ \\
\hline 2 & $\begin{array}{l}\text { Upah } \\
\text { memiliki } \\
\text { dua dimensi: } \\
\text { dunia dan } \\
\text { akherat }\end{array}$ & Tidak & $\mathrm{Ya}$ \\
\hline 3 & $\begin{array}{l}\text { Upah } \\
\text { berdasarkan } \\
\text { prinsip } \\
\text { keadilan } \\
\text { (justice) }\end{array}$ & $\mathrm{Ya}$ & $\mathrm{Ya}$ \\
\hline 4 & $\begin{array}{l}\text { Upah } \\
\text { diberikan } \\
\text { berdasarkan } \\
\text { prinsip } \\
\text { kelayakan }\end{array}$ & $\mathrm{Ya}$ & $\mathrm{Ya}$ \\
\hline
\end{tabular}

Namun jika dilihat dari persamaan maka ada persamaan diantara konsep Upah antara Barat dan Islam adalah; pertama, prinsip keadilan (justice), dan kedua, prinsip kelayakan (kecukupan).

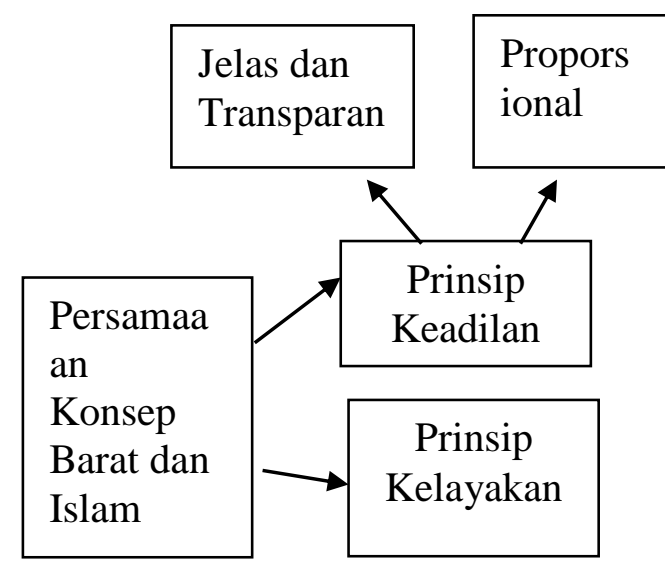

Gambar 1, Persamaan Konsep Barat dan Islam

1. ADIL, Organisasi yang menerapkan prinsip keadilan dalam pengupahan mencerminkan rganisasi yang dipimpin oleh orang-orang bertaqwa. Konsep adil ini merupakan ciri-ciri organisasi yang bertaqwa. Al-Qur'an menegaskan : "Berbuat adillah, karena adil itu lebih dekat kepada Taqwa". (QS. Al-Maidah : 8).

2. ADIL bermakna JELAS dan TRANSPARAN, "Hai orang-orang yang beriman, apabila kamu bemua'malah tidak secara tunai untuk waktu yang ditentukan, hendaklah kamu menuliskannya. Dan hendaklah seorang penulis diantara kamu menuliskannya dengan benar. Dan janganlah penulis enggan menuliskannya sebagaimana Allah mengajarkannya, maka hendaklah ia menulis dan hendaklah orang yang 
berhutang itu mengimlakkan (apa yang akan ditulis itu), dan hendaklah ia bertaqwa kepada Allah Tuhannya, dan janganlah ia mengurangi sedikitpun daripada hutangnya. Jika yang berhutang itu orang yang lemah akalnya atau lemah (keadaannya) atau dia sendiri tidak mampu mengimlakkan, maka hendaklah walinya mengimlakkan dengan jujur.

3. ADIL bermakna PROPORSIONAL. "Dan bagi masing-masing mereka derajat menurut apa yang telah mereka kerjakan dan agar Allah mencukupkan bagi mereka (balasan) pekerjaan-pekerjaan mereka sedang mereka tiada dirugikan." (QS. AlAhqaf : 19).

"Dan kamu tidak dibalas, melainkan dengan apa yang telah kamu kerjakan." (QS. Yaasin : 54). "Bahwasanya seorang manusia tiada memperoleh selain apa yang telah iusahakannya." (QS. An-Najm : 39).

Ayat-ayat ini menegaskan bahwa pekerjaan seseorang akan dibalas menurut berat pekerjaannya itu. Konteks ini yang oleh pakar manajemen Barat diterjemahkan menjadi equal pay for equal job, yang artinya, upah yang sama untuk jenis pekerjaan yang sama. Jika ada dua orang atau lebih mengerjakan pekerjaan yang sama, maka upah mereka mesti sama.

LAYAK, Jika Adil berbicara tentang kejelasan, transparansi serta proporsionalitas ditinjau dari berat pekerjaannya, maka Layak berhubungan dengan besaran yang diterima.

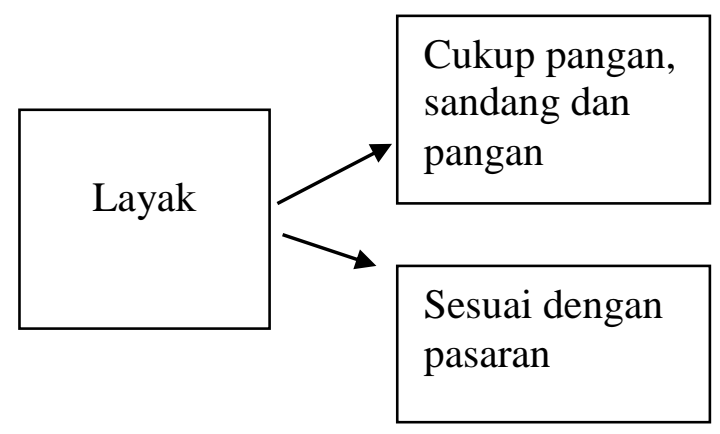

Gambar 2.Layak Dalam Syariah

1. LAYAK bermakna CUKUP PANGAN, SANDANG, PAPAN.Jika ditinjau dari hadits yang diriwayatkan oleh Abu Dzar bahwa Rasulullah s.a.w bersabda : "Mereka (para budak dan pelayanmu) adalah saudaramu, Allah menempatkan mereka di bawah asuhanmu; sehingga barang siapa mempunyai saudara di bawah asuhannya maka harus diberinya makan seperti apa yang dimakannya (sendiri) dan memberi pakaian seperti apa yang dipakainya (sendiri); dan tidak membebankan pada mereka dengan tugas yang sangat berat, 
dan jika kamu membebankannya dengan tugas seperti itu, maka hendaklah membantu mereka (mengerjakannya)." (HR. Muslim).Konsep inilah yang sangat berbeda dengan konsep upah menurut Barat. Konsep upah menurut Islam, tidak dapat dipisahkan dari konsep moral. Mungkin sah-sah saja jika gaji seorang pegawai di Barat sangat kecil karena pekerjaannya sangat remeh (misalnya cleaning service). Tetapi dalam konsep Islam, meskipun cleaning service, tetap faktor LAYAK menjadi pertimbangan utama dalam menentukan berapa upah yang akan diberikan.

\section{LAYAK bermakna SESUAI DENGAN} PASARAN "Dan janganlah kamu merugikan manusia akan hak-haknya dan janganlah kamu merajalela di muka bumi membuat kerusakan." (QS. AsySyua'ra 26 : 183). Ayat ini bermakna bahwa janganlah seseorang merugikan orang lain, dengan cara mengurangi hak-hak yang seharusnya diperolehnya. Dalam pengertian yang lebih jauh, hak-hak dalam upah bermakna bahwa janganlah mempekerjakan upah seseorang, jauh dibawah upah yang biasanya diberikan. (Shihab, Quraisy. 2002. ).

Dari uraian Upah menurut Konsep Islam diatas, maka dapat digambarkan bagaimana konsep Upah dalam Islam berdasarkan konsep Syariah memiliki
2 dimensi yaitu dimensi dunia dan dimensi akherat. ( Qardhawi,yusuf: 1997).

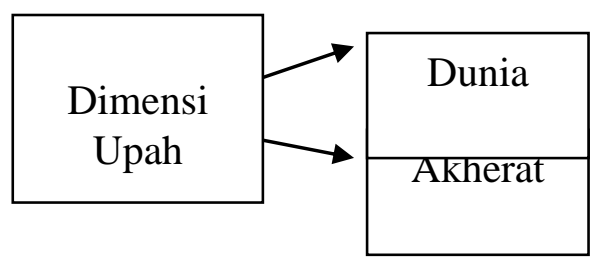

Gambar 3. Dimensi Upah dalam Konsep Syaria

Untuk menerapkan upah dalam dimensi dunia, maka konsep moral merupakan hal yang sangat penting agar pahala dapat diperoleh sebagai dimensi akherat dari upah tersebut. Jika moral diabaikan, maka dimensi akherat tidak akan tercapai. Oleh karena itulah konsep moral diletakkan pada kotak paling luar, yang artinya, konsep moral diperlukan untuk menerapkan upah dimensi dunia agar upah dimensi akherat dapat tercapai. Dimensi upah di dunia dicirikan oleh 2 hal, yaitu adil dan layak. Adil bermakna bahwa upah yang diberikan harus jelas, transparan dan proporsional. Layak bermakna bahwa upah yang diberikan harus mencukupi kebutuhan pangan, sandang dan papan serta tidak jauh berada di bawah pasaran. Aturan manajemen upah ini perlu didudukkan pada posisinya, agar memudahkan 
bagi kaum muslimin atau pengusaha muslim dalam mengimplementasikan manajemen syariah dalam pengupahan karyawannya di perusahan.(Arep dan Tanjung,2003) .

\section{KESIMPULAN}

Berdasarkan pembahasan diatas maka dapat disimpulkan :

1. Upah menurut Barat adalah Upah atau Gaji biasa, pokok atau minimum dan setiap emolumen tambahan yang dibayarkan langsung atau tidak langsung, apakah dalam bentuk uang tunai atau barang, oleh pengusaha kepada pekerja dalam kaitan dengan hubungan kerja. Sedangkan Upah menurut Islam adalah imbalan yang diterima seseorang atas pekerjaannya dalam bentuk imbalan materi di dunia (adil dan layak) dan dalam bentuk imbalan pahala di akherat (imbalan yang lebih baik).

2. Perbedaan pandangan terhadap Upah antara Barat dan Islam terletak dalam 2 hal : pertama, Islam melihat Upah sangat besar kaitannya dengan konsep Moral, sementara Barat tidak. Kedua, Upah dalam Islam tidak hanya sebatas materi (kebendaan atau keduniaan) tetapi menembus batas kehidupan, yakni berdimensi akherat yang disebut dengan Pahala, sementara Barat tidak.
Adapun persamaan kedua konsep Upah antara Barat dan Islam terletak pada prinsip keadilan (justice) dan prinsip kelayakan (kecukupan).

3. Rambu-rambu pengupahan dalam Islam ada 2 yakni adil dan layak. Adil bermakna 2 hal ; (1) jelas dan transparan, (2) proporsional. Sedangkan Layak bermakna 2 hal;(1), cukup pangan, sandang dan papan, (2), sesuai dengan pasaran.

\section{DAFTAR PUSTAKA}

AL-A'LIM, Al-Qur'an dan Terjemahannya, Edisi Ilmu Pengetahuan. PT. Mizan Pustaka, Cetakan ke-5 (Bandung, 2010)

Ahmad S. Ruky, Manajemen Penggajian dan Pengupahan Karyawan Perusahaan. Gramedia Pustaka Utama (Jakarta, 2001) hal 9.

Abdul Wahhab Abdul Aziz As- Syaisyani. Huququl Insan Wa Hurriyyatul Asasiyah Fin Nidzomil Islami Wa Nudzumil A'siroti hal 464.

Arep, Ishak dan Hendri Tanjung. 2003. Manajemen Sumberdaya Manusia. Cet. Kedua. Penerbit Universitas Trisakti. Jakarta.

Davis,keith \& newstrom, john, Perilaku dalam Organisasi, Penertbit Erlangga, 1995.

Desler, Gary, Manajemen Sumber Daya Manusia, PT,Indeks Gramedia, Jakarta

Yusuf Qardhawi, Pesan Nilai dan Moral dalam Perekonomian Islam, 2001 
Qardhawi, Syeikh Yusuf . 1997. Pesan Nilai dan Moral dalam Perekonomian Islam. Robbani Press. Jakarta

Shihab, Quraisy. 2002. Tafsir Al-Misbah Pesan, Kesan dan Keserasian Al-Qur'an. Penerbit Lentera Hati. Jakarta.

Shabuni, Muhammad Ali As-. 1995. Shafwatut-Tafasir. Dar Ehia Al-Thourath Al-Arabi. Beirut.
Sugiyono. 2017. Metode Penelitian Bisnis. Pendekatan Kuantitatif, Kualitatif, Kombinasi, dan R\&D. Alfabeta, Bandung

Tropman E. John. 2001. The Compensation Solution. How to Develop an Employee-Driven Rewards System. John Wiley \& Sons, Inc. 